\title{
EDUCAÇÃO INTERCULTURAL CRÍTICA E SUAS POTENCIALIDADES PARA OUTRA GESTÃO ESCOLAR
}

\author{
CRITICAL INTERCULTURAL EDUCATION AND ITS POTENTIALITIES FOR ANOTHER \\ SCHOOL MANAGEMENT
}

\section{EDUCACIÓN INTERCULTURAL CRÍTICA Y SUS POTENCIALIDADES PARA OTRA GESTIÓN ESCOLAR}

Zenaide Borre Kunrath ${ }^{1}$; Elcio Cecchetti ${ }^{2}$

\section{RESUMO}

No intento de contribuir para a transformação intercultural da gestão escolar, este trabalho tem como objetivo compreender como gestores escolares de três escolas públicas situadas no município de Chapecó/SC concebem, narram e se posicionam frente a problemáticas decorrentes da relação entre os(as) diferentes no cotidiano escolar. A investigação é de abordagem qualitativa e mobilizou dois tipos de pesquisa: a bibliográfica, especialmente de autores do campo da interculturalidade crítica; e de campo, realizada por meio de entrevistas semiestruturadas com gestores, orientadores e professores das escolas estudadas. Inicialmente, o trabalho conceitua educação intercultural crítica para destacar suas potencialidades para outra gestão escolar. No segundo tópico, propõe alguns princípios para uma gestão intercultural da escola. Por fim, analisa os dados coletados a partir do referencial teórico adotado. Os resultados indicam que a educação intercultural crítica se apresenta como uma possibilidade para a gestão da diversidade em instituições complexas e diversas como a escola pública. Apontam a necessidade de uma política pública que estimule o reconhecimento dos diferentes, problematize relações desiguais de poder e criem condições efetivas para o exercício do diálogo. Conclui que existem muitas ações e intenções positivas em curso nas escolas estudadas, porém insuficientes para superar uma cultura escolar assentada nos paradigmas da exclusão, padronização e monoculturalidade.

PALAVRAS-CHAVE: Gestão escolar. Educação intercultural crítica. Escola pública.

\footnotetext{
${ }^{1}$ Mestre em Educação - Universidade Comunitária da Região de Chapecó (Unochapecó). Chapecó, SC - Brasil. Docente - Centro Universitário Leonardo da Vinci (Uniasselvi). Indaial, SC - Brasil E-mail: pzenaideborre@hotmail.com

${ }^{2}$ Doutor em Educação - Universidade Federal de Santa Catarina (UFSC). Florianópolis, SC - Brasil. Docente do Mestrado em Educação - Universidade Comunitária da Região de Chapecó (Unochapecó). Chapecó, SC - Brasil. E-mail: elcio.educ@gmail.com Submetido em: 02/02/2021 - Aceito em: 06/08/2021
}

(C) ETD-Educação Temática Digital Campinas, SP $\quad$ v.23 n.3 $\quad$ p. 658-676 jul./set.2021




\section{ABSTRACT}

In an attempt to contribute to the intercultural transformation of school management, this work aims to understand how school managers from three public schools located in Chapecó/SC conceive, narrate and position themselves in the face of problems arising from the relationship between the different ones in the school routine. The approach is qualitative, semi-structured and it recruited two types of research: bibliographic, especially by authors in the field of critical interculturality; and field research, performed through semistructured interviews with managers, supervisors and teachers of the schools studied. At first, this work presents the concept of critical intercultural education in order to highlight its potentialities for another scholar management. In its second topic, it proposes some principles for an intercultural management of schools. As a conclusion, it analyzes data collected from the theoretical references adopted. The results indicated that the intercultural education presents itself as a possibility for managing diversity in complex and diverse institutions such as the school. They point to the need for a public policy that encourages the recognition of the different, problematizes unequal power relations and creates effective conditions for the exercise of dialogue. It concludes that there are many positive actions and intentions underway in the schools studied, but insufficient to overcome a school culture based on the paradigms of exclusion, standardization and monoculturality.

KEYWORDS: School management. Critical intercultural education. Public school.

\section{RESUMEN}

Con la intención de contribuir para la transformación intercultural de la gestión escolar, ese trabajo tiene como objetivo comprender como gestores escolares de tres escuelas públicas situadas en la ciudad de Chapecó/SC conciben, narran y se posicionan frente las problemáticas decurrentes de la relación entre los(as) diferentes en el cotidiano escolar. La investigación es de abordaje cualitativa y movilizó dos tipos de pesquisa: la bibliográfica, especialmente de autores del campo de la interculturalidad crítica; y de campo, realizada por medio de entrevistas semiestructuradas con gestores, orientadores y profesores de las escuelas estudiadas. Inicialmente, el trabajo conceptúa educación intercultural crítica para destacar sus potencialidades para otra gestión escolar. En un según tópico, propone algunos principios para una gestión intercultural de la escuela. Al final, analiza los datos a partir del referencial teórico adoptado. Los resultados indicaron que la educación intercultural crítica se presenta como una posibilidad para la gestión de la diversidad en instituciones complejas y diversas con la escuela pública. Apuntan la necesidad de una política pública que estimule el reconocimiento de los diferentes, problematice las relaciones desiguales de poder y generen condiciones efectivas para el ejercicio del diálogo. Concluye que existen muchas acciones e intenciones positivas en corso en las escuelas estudiadas, pero insuficientes para superar una cultura escolar asentada en los paradigmas de la exclusión, normalización y monoculturalidad.

PALAVRAS-CLAVE: Gestión escolar. Educación intercultural crítica. Escuela pública.

(C) ETD-Educação Temática Digital Campinas, SP $\quad$ v.23 n.3 $\quad$ p. 658-676 jul./set.2021




\section{INTRODUÇÃO}

As sociedades contemporâneas são constituídas pela diversidade de identidades, etnias, grupos, crenças e expressões culturais, que se manifestam sob distintas concepções de vida e de mundo nos mais variados espaços socioculturais, incluindo o cotidiano escolar, por meio de uma multiplicidade de sentidos, significados, princípios e valores. Todavia, historicamente, a convivência com os(as) diferentes e as diferenças ${ }^{3}$ se constitui em um processo complexo e desafiador. Incontáveis conflitos, exclusões, desigualdades, injustiças e violências indicam que a relação com o(a) outro(a) é uma das grandes problemáticas da humanidade (CECCHETTI; OLIVEIRA, 2015).

Diante disso, espaços formais de ensino, tais como as escolas e as universidades, possuem a função social de contribuir para o acolhimento e reconhecimento das alteridades, fomentando a convivência intercultural e a desnaturalização de estereótipos, preconceitos e intolerâncias. Contudo, o reconhecimento das diferenças requer que os processos educativos se ancorem em outros paradigmas epistemológicos, que melhor possibilitem distinguir as diferenças que inferiorizam daquelas que não inferiorizam, no contexto social de desigualdade e de exclusões no qual coexistem (SOUSA SANTOS, 1999). O desafio é mobilizar outras formas de relacionamento com as diversidades que permitam compreendê-las em suas bases simbólicas e epistemológicas, abrindo possibilidades para diálogos e interações de reciprocidade entre elas.

Para Candau (2009), o desafio é transformar as diferenças em vantagem pedagógica, tanto na perspectiva da elaboração das práticas quanto do exercício dos direitos sociais. Trata-se de convocar os sistemas formais de ensino a criarem espaços, ações e atividades que fomentem a superação da exclusão e da injustiça, o que implica, necessariamente, em uma mudança estrutural e cultural destas instituições, para que melhor acolham todos os estudantes, sejam quais forem as suas identidades.

Por conta disso, propomos a transformação intercultural da cultura escolar, já que historicamente ela não foi constituída para levar em conta a questão da diversidade. Como afirma Sacristán (1995, p. 86), "Ou se modifica a forma de entender e praticar a cultura dominante no ensino ou a integração de outras culturas não dominantes será muito difícil, senão impossível". Nesse intento, muitas reflexões, formações e ações foram empreendidas

\footnotetext{
${ }^{3}$ Diferença aqui é entendida não apenas como um conceito filosófico ou uma forma semântica, mas como uma realidade concreta, um processo humano, histórico e social, que os sujeitos empregam em suas práticas cotidianas (KOCH, 2007).
}

(C) ETD- Educação Temática Digital Campinas, SP $\quad$ v.23 n.3 $\quad$ p. 658-676 jul./set.2021


nas últimas décadas, por diferentes coletivos e sujeitos, para construir propostas críticas de educação intercultural, a fim de construir um novo projeto societário, assentado em relações de reconhecimento dos diferentes e das diferenças. Inúmeras foram as iniciativas que buscaram traduzir e incorporar a perspectiva intercultural no cotidiano escolar, sobretudo na área do currículo, nos processos de formação inicial e continuada de professores, na produção e revisão de materiais didáticos e paradidáticos. Entretanto, um elemento muito importante da oferta educativa não tem recebido a devida atenção no debate concernente ao avanço da educação intercultural: a gestão escolar.

Para compreender o quanto o tema da gestão intercultural da escola foi alvo de pesquisas científicas, realizamos consulta no Catálogo de Teses e Dissertações da Comissão de Aperfeiçoamento de Pessoal de Nível Superior (CAPES) e na Biblioteca Digital Brasileira de Teses e Dissertações (BDTD). O recorte temporal abrangeu o período de 2000 a 2020. Utilizando o descritor 'gestão intercultural', localizamos 10 trabalhos publicados, dos quais, após leitura dos títulos e resumos, apenas cinco abordavam o tema de forma explícita, como podemos visualizar no Quadro 1.

Quadro 1 - Dissertações e teses relacionadas à "gestão intercultural" (2010-2020)

\begin{tabular}{|c|c|c|c|c|}
\hline Autor/Ano & Título & $\begin{array}{l}\text { Tipo do } \\
\text { estudo }\end{array}$ & Área & IES/PPG \\
\hline $\begin{array}{l}\text { Julio Cesar dos } \\
\text { Santos (2004) }\end{array}$ & $\begin{array}{l}\text { Gestão intercultural: um estudo de } \\
\text { caso no processo de privatização da } \\
\text { Light RJ }\end{array}$ & Dissertação & Gestão & UFRRJ \\
\hline $\begin{array}{l}\text { Terezinha Furtado } \\
\text { de Mendonça (2006) }\end{array}$ & $\begin{array}{l}\text { Gestão escolar: interculturalidade e } \\
\text { protagonismo na escola indígena }\end{array}$ & Dissertação & Educação & UFMT \\
\hline $\begin{array}{l}\text { João Henrique } \\
\text { Gamond Saravia } \\
\text { (2010) }\end{array}$ & $\begin{array}{l}\text { Gestão intercultural: a experiência } \\
\text { dos executivos brasileiros no México }\end{array}$ & Dissertação & $\begin{array}{l}\text { Gestão } \\
\text { Empresarial }\end{array}$ & FGV \\
\hline $\begin{array}{l}\text { Juliana Regiani } \\
\text { Olbrzymek (2012) }\end{array}$ & $\begin{array}{l}\text { Gestão intercultural: um estudo de } \\
\text { caso com empresas catarinenses }\end{array}$ & Dissertação & $\begin{array}{l}\text { Administraç } \\
\text { ão }\end{array}$ & UFSC \\
\hline $\begin{array}{l}\text { Julia Rodrigues } \\
\text { Nobre de Oliveira } \\
\text { (2013) }\end{array}$ & $\begin{array}{l}\text { O gestor e os desafios culturais } \\
\text { regionais }\end{array}$ & Dissertação & $\begin{array}{l}\text { Administraç } \\
\text { ão }\end{array}$ & UFBA \\
\hline $\begin{array}{l}\text { Beatriz Leite } \\
\text { Gustmann de Castro } \\
\text { (2018) }\end{array}$ & $\begin{array}{l}\text { Trabalho e fluxos migratórios: } \\
\text { elementos da interculturalidade no } \\
\text { contexto organizacional a partir da } \\
\text { inserção de haitianos }\end{array}$ & Dissertação & $\begin{array}{l}\text { Desenvolvim } \\
\text { ento } \\
\text { Regional }\end{array}$ & UTFPR \\
\hline
\end{tabular}

Fonte: Os autores (2021)

Como é possível perceber, com exceção de um trabalho, os demais abordam o tema

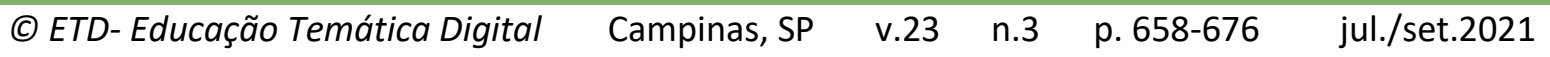


da gestão intercultural na perspectiva da administração, gestão de empresas e organizações, já que estas operam com diferentes mercados e lidam com a diversidade cultural em função de suas transações comerciais internacionais. Portanto, a partir deste diagnóstico, constatamos a escassa produção acerca do tema da gestão intercultural no campo educativo.

No intento de contribuir para a transformação intercultural da gestão escolar, este trabalho tem como objetivo compreender como gestores escolares de três escolas públicas situadas no município de Chapecó/SC $\mathrm{SC}^{4}$ concebem, narram e se posicionam em face de problemáticas decorrentes da relação entre os(as) diferentes no cotidiano escolar. Metodologicamente, entrevistamos três gestores(as), três orientadores(as) e três professores(as) entre os meses de março e abril de 2020.5 Todas as entrevistas foram gravadas e transcritas com base nas medidas necessárias para assegurar o anonimato das instituições e pessoas envolvidas. ${ }^{6}$ Para possibilitar a análise dos dados, fizemos a proposição de alguns princípios para a gestão intercultural escolar, a partir de referências teóricas do campo da educação intercultural crítica.

Considerando o objetivo anunciado, no primeiro tópico, conceituamos educação intercultural crítica para destacar suas potencialidades para outra gestão escolar. No segundo item, exploramos alguns princípios para uma gestão intercultural da escola. Por fim, analisamos os dados coletados e finalizamos apontando algumas considerações.

\section{EDUCAÇÃO INTERCULTURAL CRÍTICA E A GESTÃO ESCOLAR}

A interculturalidade, como movimento político-epistemológico, emergiu no contexto latino-americano ao final da década de 70 e, paulatinamente, vem sendo utilizada em diversos âmbitos sociais, passando a ocupar lugar central nas propostas de superação de processos de exclusão e desigualdade a que muitos sujeitos/grupos foram submetidos em decorrência tanto do colonialismo quanto do capitalismo neoliberal. Desde então, a interculturalidade tem fundamentado um conjunto de propostas que objetivam fomentar "o potencial criativo e vital resultante das relações entre diferentes agentes e seus respectivos contextos" (FLEURI, 2005, p. 93).

\footnotetext{
${ }^{4}$ Os critérios de inclusão e exclusão das escolas pesquisadas foram os seguintes: 1o: estar localizada em área urbana do município; 2o possuir mais de 500 alunos(as) matriculados(as); 3ㅇ: constar no plano de gestão da escola menções aos conceitos de interculturalidade, diversidade e diferenças.

${ }^{5} \mathrm{O}$ projeto de pesquisa foi encaminhado ao Comitê de Ética em Pesquisa (CEP) sendo aprovado sob o número 25980319.5.0000.0115. Devido a pandemia do Covid-19, as entrevistas ocorreram de forma remota (via Skype). ${ }^{6}$ Para assegurar a lisura do processo, firmamos o Termo de Consentimento Livre e Esclarecido, o Termo de Compromisso para Uso de Dados em Arquivo e o Termo de Consentimento para Uso de Imagem e/ou Voz.
}

(C) ETD-Educação Temática Digital Campinas, SP $\quad$ v.23 n.3 $\quad$ p. 658-676 jul./set.2021 
Walsh (2010), contudo, aponta que, a partir dos anos 1990, a interculturalidade se converteu em uma "moda". O tema está presente nas políticas públicas, reformas educativas e constitucionais, tornando-se um eixo importante tanto na esfera nacional quanto transnacional. Ainda que isso possa ser resultado das lutas dos movimentos sociais, políticos e dos povos originários, o termo foi cooptado por organismos multinacionais, tais como a Unesco, o Banco Mundial e a OCDE, bem como por governos e instituições nacionais, para atender necessidades administrativas, comerciais e institucionais. Daí advém a necessidade de fazer uma distinção entre uma "interculturalidade funcional" posta a serviço do poder dominante e outra concebida como um projeto político de transformação social e de questionamento das relações assimétricas de poder. Por conseguinte, é necessário assumir a interculturalidade a partir de uma perspectiva crítica, com a finalidade de refundar as estruturas sociais que inferiorizam, subalternam, invisibilizam, violentam e desumanizam o(a) outro(a).

No âmbito da "interculturalidade funcional", segundo a referida autora (2010), a potencialidade do reconhecimento reduz-se à mera inclusão de sujeitos na estrutura societária vigente, que, como sabemos, se assenta e reproduz a lógica da desigualdade. Ao contrário, a interculturalidade crítica parte do "problema do poder, seu padrão de racialização e a diferença que foi construída em função dele" (2010, p. 88).

De acordo com Fornet-Betancourt (2015, p. 29), "A interculturalidade tem lugar quando duas ou mais culturas entram em interação de uma forma horizontal e sinérgica. Para tal nenhum dos grupos deve se encontrar acima de qualquer outro que seja". Isso implica uma tomada de posição ética a favor da convivência com as diferenças e com os(as) diferentes, muito embora o aparecimento de conflitos seja algo inevitável, os quais devem ser resolvidos por meio do reconhecimento mútuo.

Na concepção de Candau (2009, p. 9), a interculturalidade crítica questiona as

[...] desigualdades construídas ao longo da história entre diferentes grupos sócioculturais, étnico-raciais, de gênero, entre outros. Parte-se da afirmação de que a interculturalidade aponta à construção de sociedades que assumam as diferenças como constitutivas da democracia e sejam capazes de construir relações novas, verdadeiramente igualitárias entre os diferentes grupos sócio-culturais, o que supõe empoderar aqueles que foram historicamente inferiorizado.

A partir desses pressupostos, a educação intercultural crítica desponta como um projeto político que contribui para o reconhecimento dos direitos e da dignidade de qualquer pessoa ou grupo social. Fleuri (2003, p. 73) destaca que "a educação intercultural, não sendo uma disciplina, coloca-se como uma outra modalidade de pensar, propor, produzir e dialogar com as relações de aprendizagem, contrapondo-se àquela tradicionalmente polarizada, homogeneizante e universalizante". Por esse motivo, a proposta da educação intercultural se

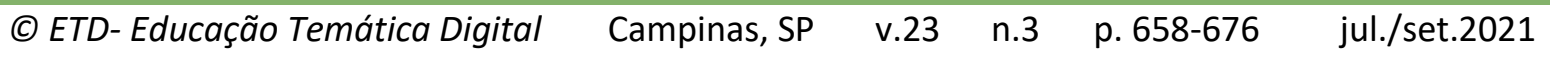


constrói de mãos dadas com a pedagogia decolonial ${ }^{7}$, como estratégia que busca construir relações de saber, ser, poder e viver radicalmente distintas.

Para tanto, a escola é desafiada a desconstruir práticas homogeneizadoras que não reconhecem as diferenças, para construir experiências pedagógicas a partir de paradigmas educacionais "outros", mobilizando as comunidades educativas na construção de projetos político-pedagógicos relevantes para cada contexto. Nesse horizonte, a perspectiva intercultural crítica pode oferecer contribuições especialmente relevantes (CANDAU, 2016).

Entretanto, frequentemente, as práticas de gestão escolar reproduzem o caráter monocultural da cultura escolar. Isso ocorre porque, como assinala Candau (2012), a escola atual é herdeira da escola do século XIX, que foi encarregada de forjar uma identidade nacional, homogeneizando as diferenças. Para superar esse quadro, propomos uma gestão escolar intercultural que seja sensível às expressões da diversidade, o que implica em conhecer o contexto em que escola se encontra inserida, seus sujeitos e suas problemáticas.

Segundo Cury (2007, p. 493), o termo gestor(a) decorre do latim gestatio, ou seja, gestação, "ato pelo qual se traz dentro de si algo novo e diferente: um novo ente". Desse modo, gerir implica trazer, apresentar ou fazer algo novo. Na escola, gestar requer a criação de condições e ambiente favorável para a formação integral dos estudantes e, para isso, a gestão da escola necessita estar atenta e reconhecer os que nela transitam.

O(a) gestor(a) é certamente um agente de referência na escola, um(a) representante da comunidade escolar, cuja responsabilidade é contribuir para que a instituição cumpra sua função social assegurando uma formação integral aos estudantes. Isso implica, inicialmente, em trabalhar em favor da aprendizagem de todos(as) e a combater os elementos que reproduzem o fracasso escolar. Geralmente, os(as) primeiros(as) a serem excluídos(as), reprovados(as) e evadidos(as) da escola são os(as) estudantes que possuem identidades e condições socioculturais que não se "encaixam" no padrão monocultural preterido pela cultura escolar. Candau (2016, p. 818) registra que a "lógica da homogeneização impera, apoiada particularmente na multiplicação de instrumentos avaliativos com base em testes padronizados sobre determinadas áreas curriculares, que estimulam a homogeneização do sistema".

\footnotetext{
${ }^{7}$ Pedagogia decolonial é um projeto político, social, epistêmico e ético, que considera a diferença em termos relacionais, com seu vínculo histórico-político-social e de poder, para construir e afirmar processos, práticas e condições diferentes. Dessa maneira, a pedagogia é entendida para além do sistema educativo, do ensino e transmissão do saber, como processo e prática sócio-político produtivo e transformador assentado nas realidades, subjetividades, histórias e lutas das pessoas, vividas num mundo regido pela estrutura colonial (WALSH; OLIVEIRA; CANDAU, 2018).
}

(C) ETD-Educação Temática Digital Campinas, SP $\quad$ v.23 n.3 $\quad$ p. 658-676 jul./set.2021


Nesse sentido, cabe à gestão escolar promover estratégias interculturais que promovam processos centrados em aprendizagens significativas com base no princípio do reconhecimento e da valorização das diferenças culturais. Para isso, é imprescindível

\begin{abstract}
[...] conhecer melhor o mundo cultural dos alunos; perceber que os alunos trazem experiências que são significativas e importantes; relatos de histórias de vida; observar a cultura da escola, buscando elementos que possam quebrar a homogeneidade; refletir sobre os conhecimentos que se pretende construir e problematizar as formas de construção desses conhecimentos na escola; ouvir e prestar a atenção aos diferentes atores presentes na escola, se aproximar e sentir o outro; descobrir no corpo docente quem são as pessoas mais sensíveis ao tema; estabelecer parcerias. (CANDAU, 2016, p. 815).
\end{abstract}

Conhecer os(as) estudantes e suas realidades é fundamental para uma prática pedagógica intercultural, de modo a contribuir para a construção de uma educação mais justa e inclusiva. Afinal, a escola é um espaço público no qual devem circular com liberdade diferentes modos de ser e de viver.

À luz desses pressupostos, a gestão escolar intercultural promove a participação e incentiva relações cooperativas e solidárias, combate à discriminação e o preconceito, e problematiza relações de poder que (re)produzem a exclusão e a desigualdade. Assim, o(a) gestor(a) escolar exerce papel fundamental no movimento de superação de práticas homogeneizadoras e autoritárias, fomentando um clima organizacional favorável ao diálogo e interação entre todos os sujeitos da comunidade escolar.

\title{
3 PRINCÍPIOS PARA UMA GESTÃO ESCOLAR INTERCULTURAL
}

Uma educação intercultural crítica é fundamental no processo de inclusão de todos(as), o que desafia a equipe gestora a tomar consciência das limitações e possibilidades de atuação, na busca constante do acolhimento das singularidades dos sujeitos da comunidade escolar. Em uma gestão intercultural, pessoas que se encontram em situação de desvantagem social, cultural, política, étnica, física, religiosa, econômica, entre outros, necessitam ser valorizadas em suas diferenças, rompendo com o caráter padronizador e monocultural da cultura escolar. A gestão intercultural reconhece as diferenças e problematiza relações de poder que reproduzem processos de exclusão e desigualdades.

Em vista disso, propomos quatro princípios para a construção de práticas de gestão escolar a partir dos pressupostos da educação intercultural crítica:

1. Participação: princípio que assegura o direito à liberdade de pensamento, expressão e opinião, possibilitando que toda a comunidade escolar participe e se sinta pertencente à escola. Isso implica uma gestão de perspectiva democrática, alicerçada na coletividade e na escuta dos sujeitos envolvidos com o processo educativo. A participação da
(C) ETD- Educação Temática Digital
Campinas, SP
v. 23
n. 3
p. $658-676$
jul./set.2021 
comunidade escolar é fundamental não somente na tomada de decisões, mas na construção, planejamento, desenvolvimento e avaliação do projeto político-pedagógico (PPP), para que este tenha maior engajamento dos sujeitos e atenda melhor as suas necessidades.

2. Reconhecimento das diferenças: esse princípio ancora a constituição de outras práticas pedagógicas e de gestão que se contraponham à padronização, à produção em série, à uniformidade, ao "mesmo" ou à "mesmice" (CANDAU, 2002). Esse princípio implica em considerar o(a) outro(a) como portador(a) legítimo(a) do direito à dignidade e à justiça. $O$ acolhimento dos sujeitos em suas identidades consiste em uma meta coletiva para alcançar uma convivência solidária entre os sujeitos que integram a comunidade escolar. Isso demanda a constante desnaturalização de visões e práticas hegemônicas profundamente arraigadas no cotidiano que priorizam o comum, o uniforme, o homogêneo e o universal.

3. Alteridade: princípio que considera cada sujeito como ser singular, único e irrepetível. A alteridade requer a reciprocidade entre os sujeitos, uma relação em que o "eu" e o "outro(a)" estejam irmanados na superação dos desafios comuns do contexto em que vivem, mediante o diálogo e a cooperação. De acordo com Pozzer (2013, p. 14), a alteridade remete à relação rosto-rosto, sendo "o rosto a manifestação da singularidade de cada pessoa, motivo pelo qual todo ser humano é possuidor de dignidade". A alteridade, segundo o autor, pertence ao outro(a), do qual não podemos nos apossar, apenas acolher e reconhecer. 0 rosto do(a) outro(a) interpela por uma atitude ética, que se manifesta no direito de falar e na responsabilidade do escutar, componentes centrais em um diálogo legítimo.

4. Ética intercultural: princípio relacionado a uma postura ética pautada no reconhecimento da dignidade do ser humano que se revela na alteridade. Isso implica em reconhecer como legítimos outros princípios e valores éticos para além do conceito monológico da racionalidade cristã-ocidental, abrindo assim possibilidades para o encontro intercultural entre culturas, epistemes e saberes diversos. É preciso compreender que as formas de reflexão acerca dos valores e normas variam a cada cultura ou grupo social. Segundo Salas Austrain (2003), a ética intercultural reflete sobre o sentido da vida em comum, em meio à pluralidade de princípios valorativos e normativos que caracterizam as sociedades contemporâneas. Por isso, a ética intercultural não deve buscar a pacificação ou harmonização forçada dos conflitos e controvérsias entre as diferenças, mas, ao contrário, desencadear um processo de autorreflexão crítica de si e de sua(s) cultura(s), a partir dos princípios e valores diversos proclamados pelos(as) outros(as).

Entendemos que esses quatro princípios são basilares para uma gestão escolar intercultural, pois representam a ousadia de revisar concepções e paradigmas que reproduzem processos de exclusão e desigualdade, buscando fomentar o reconhecimento

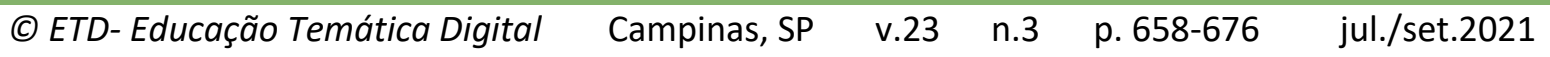


das identidades e promover percursos formativos plurais, dialógicos e interculturalmente orientados.

\title{
4 DESAFIOS PARA A GESTÃO ESCOLAR INTERCULTURAL
}

Face ao objetivo da pesquisa, que é compreender como gestores escolares de três escolas públicas situadas no município de Chapecó/SC concebem, narram e se posicionam em face de problemáticas decorrentes da relação entre os(as) diferentes no cotidiano escolar, realizamos as seguintes perguntas a cada um(a) dos(as) entrevistados(as): a) o Plano de Gestão Escolar (PGE) ${ }^{8}$ prevê alguma meta ou estratégia para acolhimento da diversidade étnico-racial, cultural, social, linguística, religiosa...?; b) como essas metas ou estratégias são colocadas em prática?; c) os estudantes são reconhecidos em suas identidades e diferenças no cotidiano da escola? Em caso negativo, que ações são necessárias para o enfrentamento desta problemática? Ao todo foram ouvidas nove pessoas, três gestores(as), três orientadores(as) e três professores(as).

Inicialmente, analisaremos os dados obtidos acerca da indagação sobre as metas ou estratégia para acolhimento da diversidade previstas nos PGE. Vejamos a manifestação do Gestor 1, que bem sintetiza as demais devolutivas:

\begin{abstract}
Para nós enquanto escola, isso é uma novidade, a questão intercultural ou a vinda desses alunos estrangeiros. Até ano passado, nós não tínhamos alunos estrangeiros, recebemos este ano, então no Plano, não foi posto especificamente a palavra acolhimento ou olhar para este diferente, mas está no Plano olhar diferente para o diferente (alunos com necessidades especiais, como: TDAH, hiperatividade, surdez, etc.) (GESTOR 1).
\end{abstract}

Compreender que as questões interculturais são uma "novidade", agudizada pela chegada dos "estrangeiros", indica que a diversidade cultural tem sido historicamente negligenciada pela gestão escolar. Isso atesta a ausência de uma sensibilidade necessária à percepção da diferença, resultado da presunção de que a "minha/nossa" identidade é norma e referência. Com isso, a diversidade de culturas, símbolos, significados, valores e práticas sociais são inviabilizadas, desperdiçadas e homogeneizadas em processos escolarizadores centrados em identidades hegemônicas fixas e padronizadas.

Uma percepção limitada acerca da diversidade cultural também fica evidente no seguinte relato:

\footnotetext{
${ }^{8}$ Em 2013, a Secretaria de Estado da Educação de Santa Catarina (SED) instituiu que o processo de escolha do(a) gestor(a) escolar ocorra por meio da eleição de Planos de Gestão Escolar (PGE), os quais são apresentados por profissionais da educação interessados(as) em ocupar essa função (SANTA CATARINA, 2019).
}

(C) ETD- Educação Temática Digital Campinas, SP $\quad$ v.23 n.3 $\quad$ p. 658-676 jul./set.2021




\begin{abstract}
Nossa escola tem um histórico de receber uma grande diversidade de alunos com necessidades especiais, por exemplo. Então, [...] já na década de oitenta nossa escola recebia alunos surdos, depois eles foram incluídos nas salas regulares. [...] Já tivemos alunos cegos, etc., hoje temos uma grande diversidade de alunos incluídos na educação especial, alunos com TDAH ou outros diagnósticos. A diversidade étnico-racial não é tão grande em nossa realidade. Este ano que recebemos, por exemplo, venezuelanos e está sendo uma experiência nova. (PROFESSORA 1).
\end{abstract}

Nesse caso, o acolhimento da diversidade encontra-se restrito ao atendimento das pessoas com deficiência, já que a "diversidade étnico-racial" teria iniciado com a chegada de imigrantes estrangeiros. Isso indica que certas identidades foram/são incorporadas pela cultura escolar na medida em que elas fazem parte do "nosso grupo". Longe de ser uma "inclusão" tranquila, a presença dos(as) deficientes no cotidiano escolar passou a ser algo "normal" após décadas de reivindicação de grupos sociais, que resultou na promoção de políticas públicas de inclusão de pessoas com deficiência na escola. Por isso, esses sujeitos recebem certa atenção e cuidado por parte dos gestores, haja vista, inclusive, as sanções legais que poderão incorrem quando da limitação ou obstáculo ao direito de acesso à educação.

Contudo, o que chama atenção é a constatação de que a "diversidade étnico-racial não é tão grande em nossa realidade". Ora, Chapecó/SC é uma cidade fundada por imigrantes italianos e alemães, os quais, com o apoio do Estado catarinense, usurparam o território tradicional indígena Kaingang e expulsaram os "caboclos" residentes da região. Palco de grandes conflitos étnico-territoriais, que eclodiram na Guerra do Contestado, o município é constituído por múltiplas identidades, culturas, idiomas e religiosidades, que parecem não ser percebidos pela gestão escolar.

Não reconhecer a diversidade é resultado do que Cortesão (2004) nomeia de "daltonismo cultural", expressão que designa a dificuldade de perceber e acolher a diversidade. Muitas vezes esse "daltonismo" se manifesta em relações dicotômicas do tipo "nós" e "eles", sendo que as atribuições da diferença são erigidas a partir de um determinado lugar que se coloca como referência. O problema é que sempre que há dualismos, um dos termos é mais valorizado do que outro: um é "norma" e o outro é "outro", um pertence e outro não, um está incluído e o outro excluído (SILVA, 2014).

A educação intercultural crítica problematiza e supera o binarismo nós $x$ eles porque entende que não somos "nós" que possuímos a legitimidade universal de determinar quem são "outros". Até porque a diferença também é "nossa" e, na relação, o "nós" é também um "eles" para o(a) outro(a). Assim, é a "nossa" própria alteridade e diferença que se expõe na relação. Deste modo, a escola pode tornar-se lugar de encontro, já que a "nossa" diferença exprime-se não como aquela portadora da "verdade". O "daltonismo cultural" é superado pela consciência da incompletude cultural, já que há incontáveis modos de ser e viver, sendo




que nenhum deles esgota as possibilidades de vir a ser do humano.

A Professora 1 destacou que a vinda dos "estrangeiros" tem proporcionado uma experiência diferente à escola. Nos últimos anos, a vinda de migrantes tem se intensificado em função de desastres ambientais, conflitos políticos, étnicos ou culturais. Desde 2010, a cidade de Chapecó/SC, por ser um polo agroindustrial do Oeste catarinense, tem recebido um grande fluxo de imigrantes, sobretudo haitianos e venezuelanos, que foram atraídos pelos postos de trabalhos em agroindústrias, frigoríficos e demais empresas da região. Ocupam, na maioria das vezes, funções braçais e recebem os mais baixos salários. Outros, infelizmente, nem se quer conseguem emprego e encontram-se em situações de vulnerabilidade social (BERNARTT et al., 2015).

Com a imigração, novos rostos e culturas adentram no cotidiano escolar da região, desafiando a tecitura de relações interculturais. A relação entre distintas identidades culturais é fundamental na construção do ser humano, pois "quando pessoas ou grupos de diferentes culturas se relacionam, o que acontece de mais importante não é a simples mistura, mas sobretudo a pluralidade dos significados, que possibilita a emergência de uma multiplicidade de sentidos em interação" (FLEURI, 2003, p. 95).

Diante disso, os(as) profissionais da educação são desafiados(as) a repensarem suas concepções e práticas de modo a acolher a diversidade e enfrentar atitudes ou práticas que afrontem a dignidade humana. A equipe de gestão tem grande responsabilidade na construção de um ambiente inclusivo, por meio de práticas e estratégias que estimulem a convivência e o reconhecimento mútuo. A Gestora 3, sensível ao tema, manifestou sua preocupação quanto a isso:

Os estrangeiros me preocupam, porque eles são muito discriminados, independente do país que eles vêm. Eu levo muito a debate essa questão, quando vamos preparar qualquer coisa na escola, levamos os dois lados a debate. O que nós podemos fazer, o que nós podemos contribuir e o que nós podemos aprender com eles (GESTORA $3)$.

Como é perceptível, a gestora mostra-se preocupada com a discriminação que os imigrantes vem sofrendo. Considerando-se a perspectiva intercultural crítica, a gestão escolar não poderá negligenciar tais acontecimentos e necessita encontrar estratégias de superação de práticas hostis aos diferentes e às diferenças. O princípio do acolhimento da diversidade implica em aprender com o(a) outro(a). A interculturalidade não é apenas um conceito, é uma prática, pois se refere, essencialmente, a reconhecer que o(a) outro(a) é portador dos mesmos direitos e deveres que nós mesmos.

Para Fornet-Betancourt (2015), é necessária outra postura ou disposição que habitue os humanos a viverem "suas" referências identitárias em relação com "outros". Trata-se de




uma atitude que impulsiona um processo de reaprendizagem e recolocação cultural que permite "[...] perceber o analfabetismo cultural do qual nós fazemos culpáveis quando cremos que basta uma cultura, a 'própria', para ler e interpretar o mundo" (p. 29). Para o autor, a proposta de uma educação intercultural não é um modismo, mas uma demanda histórica por justiça cultural, principalmente daqueles grupos que foram marginalizados, reduzidos, silenciados e invisibilizados no decorrer dos tempos, dentro e fora dos espaços escolares.

Em relação à questão sobre como metas ou estratégias de acolhimento da diversidade previstas nos PGE são colocadas em prática, vejamos a manifestação da Orientadora 3, que bem ilustra a problemática:

\begin{abstract}
Sabemos que os planos de gestão e os próprios PPP trazem esse processo de reconhecimento do sujeito, mas na prática nem sempre acontece, na sala de aula nós percebemos que as práticas tanto de avaliação quanto de aprendizagem, acabam sendo as mesmas utilizadas com os alunos brasileiros. Esse trabalho de adaptação de práticas é um trabalho que precisa ir gradualmente, é muito complexo chegar num grupo de professor que tem um longo tempo de trabalho de magistério, mudar suas práticas repentinamente. Então, eu vejo que ainda há muito o que se fazer, não só mudança nas avaliações, mas o próprio processo de aprendizado. (ORIENTADORA 3).
\end{abstract}

A Orientadora 3 denuncia que as práticas pedagógicas não estão orientadas nos princípios de uma educação intercultural crítica e que a transformação delas é um processo lento e gradual. De fato, desenvolver ações focadas no reconhecimento das múltiplas identidades requer outra compreensão sobre o processo pedagógico.

A ressignificação das práticas pedagógicas, com base nos princípios da interculturalidade, implica na reconfiguração do processo de formação de docentes, no intuito de superar mecanismos que forjam identidades e diferenças sob um paradigma homogêneo e monocultural. Enquanto a formação docente centrar-se na transmissão de um conjunto de conhecimentos padronizados desarticulados da vida social e escolar, dificilmente se desenvolverá uma educação que capacite os sujeitos a compreenderem a diversidade como parte estruturante dos processos educativos.

Com apontam Cecchetti, Pozzer e Tedesco (2020), a razão moderna ainda fundamenta os processos de formação de professores mediante a transmissão de conhecimentos de uma única base identitária, inviabilizando interações e diálogos com o mundo da vida, marcado pela diversidade de concepções, experiências, práticas e perspectivas. De modo a reproduzir - modelo escolar homogeneizante, a formação docente foi pensada e organizada estrategicamente de maneira uniforme. O privilégio dado à dimensão cognitiva, à aquisição de conteúdos fragmentados, genéricos e abstratos, frequentemente distanciados do cotidiano escolar, dificulta o reconhecimento de saberes, culturas e experiências diversas.

$\begin{array}{llllll}\text { (C) ETD-Educação Temática Digital Campinas, SP } & \text { v.23 } & \text { n.3 } & \text { p.658-676 } & \text { jul./set.2021 }\end{array}$


O paradigma da padronização dá margem ao entendimento das diferenças como desvio, patologia, anormalidade, deficiência, defasagem, desigualdade. Por outro lado, assumir a diversidade cultural significa muito mais do que um elogio às diferenças; implica em alterar relações de poder, redefinir escolhas, tomar novos rumos. Transgredir esse modelo requer "educadores subversivos" que, segundo Mota Neto (2018), desenvolvam uma pedagogia a partir das "fissuras" ou das "feridas abertas", propondo outros desenhos curriculares para a formação docente, que possibilitem estabelecer uma relação dialógica entre os(as) diferentes, de modo a favorecer a construção de modelos sustentáveis de interação entre os seres humanos. Partindo de tais premissas, os processos de formação docente poderiam mobilizar, incorporar e promover uma educação intercultural crítica, que supere os imperativos de uniformização cultural e contribua para a diminuição das violências, desigualdades e exclusões que vicejam na atualidade.

A ausência de posturas sensíveis à diversidade e abertas à novidade trazida pelo(a) outro(a) fica evidente também neste depoimento:

\begin{abstract}
Às vezes você escuta falas como, 'se ele está no Brasil tem que falar português e não crioulo/francês/inglês', mas esquecemos que somos descendentes de imigrantes. São questões a serem repensadas por cada um de nós. [...]. Muitas vezes escutamos dos nossos próprios colegas que estamos protegendo esses alunos, mas nós só queremos garantir o espaço deles na escola. Não temos só a questão dos estrangeiros, mas a questão de gênero, de dependência química, etc., mas a dificuldade de desenvolver atividades para os estrangeiros vem do não aceitar e, primeiramente a língua, porque acaba dificultando (ORIENTADORA 3).
\end{abstract}

Sabemos que, historicamente, a escola tem dificuldades para acolher pessoas que destoam dos padrões hegemônicos. Esse processo de silenciamento das identidades culturais é um dos grandes desafios às práticas pedagógicas e de gestão. Isso implica em romper com a ideia de homogeneidade que ainda impera no campo educacional.

Desenvolver uma gestão intercultural implica em superar preconceitos e discriminações, enfrentando processos cristalizados que geram exclusão e desigualdades. Para isso, os profissionais da educação necessitam reconhecer as diferenças dentro do espaço educacional, percebendo a diversidade cultural como uma riqueza, para então contribuir na formação de estudantes que valorizem o múltiplo, o diverso, o divergente. Os gestores têm um papel fundamental no sentido de criar estratégias que fomentem a interação e a convivência entre os(as) diferentes. 
Nesse intento, algumas ações já vêm sendo desenvolvidas pelas escolas:

\begin{abstract}
Temos dois projetos na escola, o primeiro seria a Festa das Nações, onde os alunos trazem comidas típicas da cultura e, isso faz desconstruir muitos preconceitos que temos. Outro projeto muito positivo, é o Festival da Primavera, ele é um festival de dança onde os alunos se dedicam muito, inclusive nossos alunos estrangeiros. Essas foram as formas de inclusão que encontramos na escola. (ORIENTADORA 3).
\end{abstract}

Ambos os projetos são muito significativos, porque buscam promover a acolhida, estimular a convivência e possibilitar a manifestação da diversidade cultural. Contudo, é importante pensar se tal esforço é desenvolvido cotidianamente ou em momentos pontuais, pois o enfrentamento da monoculturalidade deve ser algo permanente.

Essas iniciativas atestam que as instituições educativas podem ser lugares privilegiados para (re)aprendizagem intercultural mediante o estabelecimento de relações dialógicas com as diversidades. Gestores(as) e professores(as) exercem influência significativa nesse processo, criando ações e atividades que promovam o exercício do diálogo com o outro(a) e o reconhecimento das identidades culturais.

Quanto à maneira como os estudantes são reconhecidos em suas identidades e diferenças no cotidiano da escola e sobre quais ações seriam necessárias para enfrentar o preconceito, a discriminação e exclusão, a Gestora 3 afirmou ser necessário: "[...] antes de qualquer coisa, escutar. Acredito que não adianta nós querermos fazer ações mirabolantes, se não escutamos os nossos alunos. O ato de escuta é fundamental".

Além do escutar, consideramos igualmente importante problematizar o que é dito e o não dito sobre diferentes grupos e sujeitos. Cabe aos gestores(as) e professores(as) tomar posição sempre que alguém seja discriminado, anulado ou injustiçado no cotidiano escolar. Do ponto de vista de uma ética intercultural não é possível consentir em "deixar as coisas como estão", omitindo-se da responsabilidade social que o exercício da profissão implica.

Nesse sentido, a Gestora 2 destaca uma alternativa mobilizada para acolher estudantes que não falam a Língua Portuguesa:

\footnotetext{
Quando os alunos [que] chegam, os haitianos, eu tento aproximar de outros alunos que falam a língua. Peço para os pais falaram em português em casa também, não para perder a raiz, muito pelo contrário, mas eu preciso que eles falem português para nós conseguirmos entender. Nos comunicamos bastante com imagem e fazemos avaliações diferentes, porque temos um ano inteiro, quando não nos sentimos aptos a avaliar, deixamos sem nota e depois avaliamos, mas claro que explicamos para os pais que estamos com dificuldade para avaliar naquele momento (GESTORA 2).
}

C ETD-Educação Temática Digital Campinas, SP $\quad$ v.23 n.3 $\quad$ p. 658-676 jul./set.2021


A gestão escolar intercultural busca fortalecer estas iniciativas de acolhimento, fazendo uso das possibilidades contextuais para enfrentar os processos de exclusão e desigualdade. Dada a exigência da sensibilidade para com os(as) diferentes e as diferenças, a gestão pode adotar protocolos de acolhimento e orientar-se por uma ética intercultural como mediadores(as) da ação educativa.

Partindo do pressuposto de que todo(a) educando(a) possui o direito à aprendizagem e ao desenvolvimento, o que inclui o acesso ao conjunto de saberes e conhecimentos históricos produzidos pelas diferentes culturas e sociedades, toda escola precisa assegurar em seus currículos o efetivo estudo e/ou abordagem de diferentes concepções e práticas culturais, por meio da pesquisa e do diálogo crítico, autêntico e corresponsável. Isso indica que não há neutralidade no ato pedagógico (FREIRE, 2019), pois é impensável ficar indiferente diante das questões que afrontam a dignidade humana. A ética intercultural embasa a preocupação em acolher e saber conviver com diversidade, tal como podemos aferir no depoimento da Gestora 3:

[...] nós tínhamos uma turma com onze ou quinze haitianos e neste ano também têm muitos nas turmas, como, venezuelanos, haitianos, especiais. Nós sempre aprendemos muito com eles, mesmo não falando nossa língua, todos eles falam acima de três línguas, alguns dominam cinco, seis línguas. Na escola, valorizamos muito isso. Inclusive, nas escolas os alunos se propuseram a fazer oficinas e eles ensinaram a falar francês, crioulo e outras línguas, essas oficinas nós fazíamos com o integral ano passado. (GESTORA 3).

A ética intercultural nos convoca a aprender com o(a) outro(a). A troca de conhecimentos que acontece na Escola 3 é muito importante. Os(as) imigrantes sentem que são valorizados, que podem colaborar com os(as) colegas e com a escola. É preciso ressaltar que as diferenças culturais podem ser encaradas no espaço escolar como uma potência no processo de ensino-aprendizagem e estas iniciativas são fundamentais numa gestão escolar intercultural.

A iniciativa desenvolvida pela escola em foco neste texto demostra o quanto o desenvolvimento de sensibilidades interculturais pode gerar processos inclusivos, solidários e democráticos. A gestão escolar intercultural incentiva a promoção de diálogos e convivências que corroboram em novas territorialidades, propensas a reconhecer o(a) outro(a) em suas singularidades. 


\section{CONSIDERAÇÕES FINAIS}

Os resultados da pesquisa apontam para a necessidade de uma política para uma gestão intercultural da escola. É preciso estimular a relação entre os diferentes, problematizar poderes assimétricos e criar condições efetivas para o exercício do diálogo e reconhecimento. Existem ações e intenções positivas em curso, porém insuficientes para superar uma cultura escolar assentada nos paradigmas da exclusão, padronização e monoculturalidade.

Por meio das entrevistas, observamos que as estratégias de acolhimento em desenvolvimento centram-se mais no atendimento individual de sujeitos estigmatizados e não na alteração das estruturas que geram a própria exclusão. Quanto às propostas de intervenção para enfrentamento dos conflitos, discriminações e preconceitos, foram apresentadas pelos(as) entrevistados(as) diferentes metodologias; como escutar os(as) alunos(as), o Festival da Primavera e a Festa das Nações. Contudo, a partir da perspectiva da interculturalidade crítica, há outros desafios pela frente: questionar o racismo, a subalternização, a inferiorização, a xenofobia e os padrões dominantes; desenvolver entendimentos e condições para não só dialogar em condições de igualdade e respeito, mas também alimentar a criação de outros modos de ser, estar, aprender, ensinar, gestar e viver para além das fronteiras da colonialidade (WALSH, 2010).

Os resultados também indicaram que ainda existem nas escolas práticas discriminatórias e preconceituosas em relação a alunos(as) de grupos étnicos minoritários. Os(as) gestores(as) e docentes deixaram transparecer em seus discursos que ainda há um longo caminho a ser percorrido. Também demostraram que a abordagem intercultural por parte da gestão escolar é indispensável para oferecer uma educação que seja capaz de reconhecer as especificidades dos diferentes grupos, ultrapassando toda a tendência de homogeneização e de padronização que ainda está muito presente na educação escolar.

Por fim, registramos a necessidade de maior reflexão coletiva por parte da comunidade científica e dos próprios sistemas de ensino acerca de princípios para uma gestão escolar intercultural. Esperamos que o exercício que realizamos possa ser desenvolvido e aprofundado em trabalhos futuros. Eles apenas representam os primeiros passos de um longo caminho a percorrer. São como um horizonte a perseguir na construção de outros olhares sobre a gestão escolar no contexto educacional. 


\section{REFERÊNCIAS}

BERNARTT, Maria de Lourdes, et al. Movimento migratório no sul do Brasil: o caso dos haitianos no oeste catarinense. In: SEMINÁRIO INTERNACIONAL DOBRE DESENVOLVIMENTO REGIONAL: globalização em tempos de regionalização - repercussões no território, 7., 2015. Anais [...] Santa Cruz do Sul: UNISC, 2015, p. 1-23.

CANDAU, Vera Maria Ferrão. Sociedade, cotidiano escolar e cultura(s): uma aproximação. Revista Educação \& Sociedade, n. 79, ago./2002.

CANDAU, Vera Maria Ferrão. Diferenças culturais, interculturalidade e educação em direitos humanos. Educ. Soc. v. 33, n. 118, p. 235-250, jan./mar. 2012.

CANDAU, Vera Maria Ferrão. Educação intercultural na América Latina: entre concepções, tensões e propostas. Rio de Janeiro: 7letras, 2009.

CANDAU, Vera Maria Ferrão. Cotidiano escolar e práticas interculturais. Cadernos de pesquisa, v. 46, n. 161, p. 802-820, jul./set. 2016.

CECCHETTI, Elcio; OLIVEIRA, Lilian Blanck de. Diversidade religiosa e direitos humanos: conhecer, respeitar e conviver. RIDH, n. 4, p. 181-197, jun. 2015.

CECCHETTI, Elcio; POZZER, Adecir; TEDESCO, Anderson Luiz. Formação docente intercultural e colonialidade do saber. Revista del CISEN Tramas/Maepova, v.8, n.1, p. 187-200, 2020.

CORTESÃO, Luiza. O arco-íris e o fio da navalha: problemas da educação face às culturas um olhar crítico. Grifos, n. 15, p. 89-103, 2004.

CURY, Carlos Roberto Jamil. A gestão democrática na escola e o direito à educação. RBPAE, v. 23, n. 3, p. 483-495, set./dez. 2007.

FLEURI, Reinaldo Matias. Educação intercultural: medições necessárias. Rio de Janeiro: DP\&A, 2003.

FLEURI, Reinaldo Matias. Intercultura e educação. Educação, Sociedade \& Culturas, n. 23, p. 91-124, 2005.

FORNET-BETANCOURT, Raúl. O intercultural: o problema de sua definição. In: CECCHETTI, E.; PIOVEZANA, L. Interculturalidade e educação: saberes, práticas e desafios. Blumenau: Edifurb, 2015. p. 25-30.

FREIRE, Paulo. Pedagogia da autonomia: saberes necessários à prática educativa. 69. ed. São Paulo: Paz e Terra, 2019.

(C) ETD- Educação Temática Digital Campinas, SP $\quad$ v.23 n.3 $\quad$ p. 658-676 jul./set.2021


$\mathrm{KOCH}$, Simone Riske. Discurso e ensino religioso: um olhar a partir da diferença. 2007. $116 \mathrm{f}$. Dissertação (Mestrado) - Curso de Mestrado em Educação. Universidade Regional de Blumenau, Blumenau, 2007. Disponível em:

https://bu.furb.br//docs/TE/2007/318007 1 1.pdf. Acesso em: 26 jan. 2021.

MOTA NETO, J. C. da. Por uma pedagogia decolonial na América Latina: convergências entre a educação popular e a investigação-ação participativa. Arquivos Analíticos de Políticas Educativas, v. 26, n. 84, p. 1-18, 2018.

POZZER, Adecir. A formação de professores em e para direitos humanos na perspectiva filosófica de Emmanuel Levinas. Dissertação. (Mestrado em Educação). Florianópolis: Universidade Federal de Santa Catarina, 2013.

SACRISTÁN, J. Gimeno. Currículo e diversidade cultural. In: SILVA, Tomaz Tadeu da; MOREIRA, Antônio Flávio (Org.). Territórios contestados: o currículo e os novos mapas políticos e culturais. Rio de Janeiro, Vozes, 1995, p. 84-113.

SALAS ASTRAIN, Ricardo. Ética Intercultural. Ensayos de una ética discursiva para contextos culturales conflictivos. (Re)Relecturas del pensamiento latinoamericano. Santiago de Chile: Ediciones UCSH, 2003.

SANTA CATARINA. Decreto no 194, de 31 de julho de 2019. Dispõem sobre a gestão escolar da educação básica e profissional da Rede Estadual de Ensino. Florianópolis: SED, 2019.

SILVA, T. T. da. Identidade e diferença: a perspectiva dos estudos culturais. 15. ed. Petrópolis: Vozes, 2014.

SOUSA SANTOS, Boaventura de. A construção multicultural da igualdade e da diferença. Coimbra: Centro de Estudos Sociais. Oficina do CES n. 135, jan. 1999.

WALSH, Catherine. Interculturalidad crítica y educación intercultural. In: VIAÑA, Jorge; TAPIA, Luis; WALSH, Catherine. Construyendo interculturalidad crítica. La Paz: Instituto Internacional de Integración del Convenio Andrés Bello, 2010. p. 75-96.

WALSH, Catherine, OLIVEIRA, Luiz Fernandez; CANDAU, V. M. Colonialidade e pedagogia decolonial: para pensar uma educação outra. Arquivos Analíticos de Políticas educativas, v. 26 , v. 83, p. 1-11, 2018.

Revisão gramatical: Jakeline Mendes

E-mail: jakeline@unochapeco.edu.br 